\title{
Swings in Sentiment and Stock Returns: Evidence from a Frontier Market
}

\author{
M. Arifur Rahman, Lim Kok Shien, and M. Shibley Sadique
}

\begin{abstract}
We investigate the impact of noise trader sentiment on the formation of expected returns and volatility in the context of the frontier stock market of Bangladesh. Empirical results based on a GARCH-in-mean framework show that shifts in investor sentiment are significantly positively correlated with excess market returns. Evidence of this direct impact of changes in sentiment on expected returns is robust across sample periods and alternative measures of sentiment we use in the analysis. In addition, we find that the magnitude of bullish or bearish sentiment changes also exerts an indirect effect on expected returns through its asymmetric influence on the conditional volatility process. Overall, our results suggest that shifts in investor sentiment in the market represent a systematic risk factor that is priced in equilibrium.
\end{abstract}

Index Terms - Investor sentiment, volatility, excess returns.

\section{INTRODUCTION}

We undertake an empirical investigation into the potential impact of trading behavior of uninformed investors on the stock price dynamics of a frontier stock market. Unlike that of informed investors, trading decisions of uninformed investors are driven by sentiment which is not justified by currently available fundamental information about future cash flows and investment risk.

At least since John Maynard Keynes' [1] use of the analogy of a "beauty contest" to illustrate investor behavior, economists have pondered the ways in which agent sentiment can play out in the financial markets to move asset price away from fundamental value. Decades later, DeLong, Shleifer, Summers, and Waldmann [2] formalize the role of sentiment in a financial market which is populated by two categories of investors: informed traders who rationally anticipate asset value, and uninformed noise traders who experience waves of optimistic or pessimistic sentiment that is not fully justified by the facts about fundamentals at hand. They demonstrate how, aggregate demand shifts on the part of noise traders (as a result of their acting in concert) triggered by changes in sentiment can induce a systematic risk that is priced in equilibrium. In their model, noise trader sentiment is stochastic and the deviations in price from fundamental value created by changes in sentiment are unpredictable. As a

Manuscript received June 20, 2013; revised August 19, 2013. This work was supported by the the Universiti Brunei Darussalam research grant UBD/PNC2/2/RG/1(206) in financial part.

M. A. Rahman and L. K. Shien are with the Faculty of Business, Economics \& Policy Studies, Universiti Brunei Darussalam, Gadong BE1410, Brunei Darussalam (e-mail: arifur.rahman@ubd.edu.bn, kokshien.lim@ubd.edu.bn).

M. S. Sadique is with the School of Business, Curtin University, Sarawak, Malaysia (e-mail: shibley@curtin.edu.my). result, now informed investors have to take into account not only fundamental risk of investment but also the risk that investor sentiment becomes even more extreme and prices move further away from fundamental values over the holding period. This additional risk, known as the noise trader risk, renders arbitrage activity risky and prevents risk-averse informed traders from taking fully offsetting positions to correct mispricing induced by noise trading. Consequently, noise trader risk represents an additional source of systematic risk that is priced in the market.

So far a number of studies, mostly done in the context of US markets using a variety of sentiment proxies, have largely lent support to the implication of the DSSW model for asset pricing. Although contradictory, a very few recent papers provide some emerging market evidence in the context of the rapidly growing stock markets of China. We are not aware of any published research to date that has tried to understand the implications of noise trader risk in the context of a frontier stock market. In this research plan, we propose to test the asset pricing implication of DSSW model at the market level using data from Dhaka Stock Exchange (DSE), Bangladesh. ${ }^{1}$ We choose a frontier market like DSE because we consider it to be an ideal platform to test the DSSW proposition for a couple of reasons. First, compared to developed stock markets, and even some emerging markets like China and India, Bangladesh capital market is not as well organized and managed. Market regulations often fail to protect investor rights and regulate the activities of errant listed companies and market participants. The market is largely driven by unsophisticated individual retail investors who are generally information constrained, often lack the ability to shift through information due to their poor educational background, and do not have access to expert advice of financial analysts. As a result, the investment decisions of an average investor are more likely to be swayed by the swings of sentiment in response to, for example, sheer rumors and hearsay, advice of stock brokers or financial gurus, or trend chasing behavior [3]. Recently, Schmeling [4] presents evidence that the impact of on stock returns is higher for countries which have less market integrity and which are culturally more prone to herd-like behavior and overreaction. Second, unlike developed markets and many emerging markets, arbitrage opportunities for the rational investors are extremely limited in Bangladesh stock market. It operates under a complete short sale ban and there is no derivative

\footnotetext{
${ }^{1}$ There is no standards definition of frontier stock markets. These markets generally, as defined by the MSCI and S\&P, are considered to have low liquidity, low transparency, low level of foreign investments, high corruption and a weak regulatory framework. Compared with emerging markets, frontier markets are less financially and institutionally developed. Both MSCI and S\&P categorize Bangladesh as a frontier stock market.
} 
market for arbitrageurs to create artificial positions.

\section{A BRIEF REVIEW OF LITERATURE}

The efficient market hypothesis [5] is the cornerstone of classical finance theories on asset pricing. Based on the assumption of investor rationality, the efficient market hypothesis posits that prices react only to information about changes in fundaments and considers noise as a non-fundamental factor that should not have any influence on asset pricing. The argument was that an investor trading on anything but fundamental information will fall prey to rational arbitrageurs and eventually be driven out of the market. However, over the past decades relentless evidence has surfaced calling the assumption of investor rationality in question. Therefore, the noise trader model of DSSW has attracted tremendous attention of both the academics and practitioners. Investigating the impact of investor sentiment on asset returns and volatility is essential to appreciate the implications of their model for asset pricing.

The predictive power of sentiment for returns has been explored in a number of papers. Neal and Wheatley [6] examine the forecast power of three measures of individual investor sentiment: the level of discounts on closed-end funds, the net mutual fund redemptions and the ratio of odd-lot sales to purchases. They find that fund discount predicts small firm returns (but unrelated to future large firm returns), and that net fund redemptions capture the investor sentiment in fund discounts. However, they find only little indication that odd-lot ratio has return predictability. Brown and Cliff [7], by examining various direct (survey based) and indirect measures (market data derived) of sentiment, find that although sentiment levels and changes are strongly correlated with contemporaneous market returns, sentiment indicators have little predictive power for near-term future stock returns. Their evidence suggests that sentiment effect is limited to small firm returns and returns exert mush stronger influence on sentiment indicators. However, in their follow up research [8], they establish that the lack of effect predictability of sentiment in the short run does not prevent it from affecting asset values in the long run. They show that high sentiment is followed by low cumulative long run returns as asset prices revert to their fundamental value. Baker and Wurgler [9] find that the predictability of US investor sentiment is more pronounced for firms that are hard to price and thus difficult to arbitrage (e.g., growth stocks and small stocks). More recently, Schmeling [4] examine whether consumer confidence - as a proxy of individual investor sentiment - affects expected stock returns in 18 industrialized countries. He finds that sentiment negatively forecasts aggregate stock market returns on average across countries. In line with recent evidence for the US, this relation also holds for returns of value stocks, growth stocks, small stocks, and for different forecasting horizons. Interestingly, he reports some empirical evidence suggesting the impact of sentiment on stock returns is higher for countries which have less market integrity and which are culturally more prone to herd-like behavior and overreaction.

A few papers have also investigated the relationship between sentiment and volatility of returns since sentiment may affect expected returns through its impact on the market's formation of risk. Brown [10] finds that deviations from the mean level of individual investor sentiment are associated with greater volatility in closed-end fund returns. Lee, Jiang and Indro [11], using a survey based sentiment indicator, test the impact of noise trader risk on the formation of conditional volatility and expected returns and find that shifts in sentiment are negatively correlated with conditional market volatility. Using a different sentiment measure based on daily mutual fund flow data, [12] also report similar finding on sentiment on volatility relationship.

As we have noted earlier, some recent research sheds some light on the asset pricing implication of investor sentiment in the context of emerging stock markets of China. Using market turnover, closed-end fund discount and growth in the number of investor account as sentiment indicators, [13] report significant effect of changes in Chinese investor sentiment on returns and note that the volatility of returns caused by investor sentiment changes is a systematic risk. $\mathrm{Ng}$ and $\mathrm{Wu}$ [14] however find that neither the volume of trade of institutional nor individual investors demonstrates price predictability. Using a survey based measure of institutional investor sentiment, [15] report that sentiment does not predict future market movements, but a drop in sentiment increases market volatility and destabilizes markets.

In summary therefore the empirical literature tells us that investor sentiment may indeed have asset pricing implication and it is worth investigating further especially in the context of a different market organization which is markedly different from the well developed stock markets.

\section{THE FRAMEWORK OF ANALYSIS}

The main objective of the paper is to assess the asset pricing implication of the DSSW model using a frontier market data. DSSW predict that the influence of noise traders' sentiment on expected returns can be both transitory and permanent. The direction of the direct influence is determined through the interaction of what DSSW term as the price-pressure effect and the hold-more effect. Similarly, they suggest that the direction of the indirect influence results from the relative strength of the Friedman effect and the create-space effect.

The price-pressure effect implies that, when noise traders are on average bullish (bearish), their trading pushes up (down) prices when they purchase (sale) as asset. Consequently, higher (lower) purchase (sale) prices translate into lower expected returns. The effect of price pressure is therefore always negative; no matter whether noise trader sentiment is bullish or bearish. The hold-more effect, on the other hand, implies that when noise traders' become more bullish (bearish) such that they demand more (less) of risky assets, their trading increases (decreases) the level of market risk and thereby leads to higher (lower) expected returns. Therefore, noise trading increase expected returns only when noise traders are more bullish and the hold-more effect dominates the price-pressure effect. However, the net effect of bearish noise trader sentiment on expected return is always negative since these two effects become mutually reinforcing. 
In addition, the variability of misperceptions about asset's value on the part of noise traders increases price uncertainty in the market and discourage risk-averse smart money investors to confront noise traders in trading risky assets. The create-space effect refers to a situation where noise induced increased volatility tend to crowed out smart investors and create more space for noise traders to trade only among themselves and thereby help increase their returns. Therefore, this situation implies higher volatility and higher expected returns for the noise traders. The Friedman effect, on the other hand, refers to a situation where noise induced increased volatility does not prevent smart money investors from betting against and exploiting the noise traders. Since noise traders tend to herd in their investment decision, they are usually very poor market timers; meaning that they tend to buy high and sell low. As a result, if higher price uncertainty due to noise trading fail to prevent smart money from betting against the noise traders, higher volatility may also mean higher losses for the noise traders. The joint influence of the create-space effect and the Friedman effect on expected return may either be positive or negative depending on their relative importance at a particular time. Clearly, unlike the price-pressure and hold-more effects, the create-space and Friedman effects influence asset prices not directly but through an increase in volatility of returns.

To investigate the role of sentiment in DSE price process we follow [11], who employ a generalized conditional heterokedasticity $(\mathrm{GARCH})$ in-mean framework and jointly test the impact of sentiment both on the formation of conditional volatility and expected returns. Specifically, we estimate an asymmetric GARCH in-mean model ${ }^{2}$ that includes contemporaneous shifts in investor sentiment in the mean equation and lagged shifts in sentiment indicator in the conditional volatility equation. The model takes the following form:

$$
r_{t}-r_{f t}=\alpha_{0}+\alpha_{1} \sigma_{t}+\alpha_{2} \Delta S_{t}+\varepsilon_{t}
$$

where $r_{t}$ is monthly return on the market, $r_{f t}$ is the risk-free rate, $\Delta S_{t}$ is the shift in the measure of sentiment indicator, and $h_{t}$.captures the conditional volatility of market returns. In addition, in equation (1) $\varepsilon_{t} \sim N\left(0, h_{t}\right)$ and

$$
\begin{aligned}
\sigma_{t}^{2}= & \beta_{0}+\beta_{1} \varepsilon_{t-1}^{2}+\beta_{2} \varepsilon_{t-1}^{2} I_{t-1}+\beta_{3} h_{t-1} \\
& +\beta_{4}\left(\Delta S_{t-1}\right)^{2} D_{t-1}+\beta_{5}\left(\Delta S_{t-1}\right)^{2}\left(1-D_{t-1}\right)
\end{aligned}
$$

where $I_{t-1}=1$ if $\varepsilon_{t-1}<0$ and zero otherwise, and $D_{t-1}=1$ when $\Delta S_{t-1}>0$ and zero otherwise.

While the coefficient $\alpha_{2}$ in equation (1) measures the impact on sentiment changes on market returns, coefficients $\beta_{4}$ and $\beta_{5}$ gauge the impact of sentiment shifts on conditional volatility. Whether this volatility in turn affects excess returns is measured by the GARCH in-mean term $\alpha_{1}$ [17]

${ }^{2}$ Asymmetric GARCH in-mean specification is motivated by [16] and in equation (1).

In order to account for typical autocorrelation property of excess market return, we include first four lags of the series in equation (1). The equation is further augmented to account for potential day-of-the-week effect in market returns.

\section{Sentiment Measures}

Our primary measure of sentiment shift is a modified trading index (TRIN) - a measure of relative strength of trading volume in relation to advancing stocks against that of declining stocks. The original measure of TRIN, as introduced by Richard Arms in an article in Barron's in 1967, is given by

$$
\mathrm{TRIN}=\frac{A / D}{A V / D V}=\frac{D V / D}{A V / A}
$$

where $A(D)$ is the number of advancing (declining) stocks and $A V(D V)$ is advancing (declining) volume measured in number of shares. TRIN can therefore be interpreted as the ratio of the average daily volume of declining stocks to the average daily volume of the advancing stocks. Clearly, TRIN will have a neutral value of 1 when the average declining volume is exactly equal to the average rising volume on a day. Naturally, a TRIN value greater (smaller) than 1 can therefore be interpreted as representing a bearish (bullish) trading behavior of the market participants. Since the bullish (bearish) activity causes the ratio to decline (rise), TRIN in its original form actually sounds counter intuitive. In addition, as a closer look would however reveal, the lowest possible TRIN value is zero and hence it can never be more than one unit below the neutral value. In contrast, there is effectively no cap on its highest possible value. TRIN in its basic form therefore is also asymmetric by construction. In order to this asymmetric property, we use the following modified TRIN (MTRIN) measure, which is also increasing in bullish market activity:

$$
\text { MTRIN }=\ln (1 / \text { TRIN })
$$

In addition, in order to test the robustness of our results based on our intuitive MTRIN measure, we use another sentiment proxy based on a recent theoretical work [18]. They argue that, in the presence of short-sale constraint, market liquidity can be used as an indicator of investor sentiment. Although there are several different measures of liquidity, considering limited availability of a broad range of data sets on frontier markets, we find the liquidity measure proposed by Amihud [19] most suitable for use in a frontier market like the DSE. His measure is essentially an illiquidity measure that follows [20] concept of illiquidity - the price response to order flows, and requires only daily return and value of trades as its inputs to calculation. In order to convert the market level Amihud illiquidity measure to a liquidity measure (which in increasing in sentiment), we multiply its normalized $\log$ values by -1 . The first difference of this transformed Amihud measure represents our measure of sentiment shifts. 


\section{DATA AND DESCRIPTIVE STATISTICS}

In order to construct our market-wide sentiment proxies and conduct further analysis we use stock-level daily data over the period from 1 Jan 2001 through 28 Dec 2012. Our sample of 322 stocks includes dead and delisted common stocks, which helps alleviate potential survivorship bias in our results. To check the stability of results of the analysis, we split the full sample period into two sub-samples - one ranging from 2001 to 2006 and the other from 2007 to 2012. Returns are calculated as the logarithmic differences of prices times 100. Capitalization weighted returns on the portfolio of sample stocks is considered to represent the market return. Daily excess return on the market is then calculated by deducting the call money rate from the market return.

TABLE I: DESCRIPTIVE STATISTICS OF EXCESS MARKET RETURNS AND SENTIMENT PROXIES

\begin{tabular}{|c|c|c|c|}
\hline \multirow[t]{2}{*}{ Panel-A: } & \multicolumn{3}{|c|}{ Excess market return } \\
\hline & Full Smpl & $1^{\text {st }} \mathrm{SS}$ & $2^{\text {nd }} \mathrm{SS}$ \\
\hline Mean & 0.050 & 0.041 & 0.057 \\
\hline Median & 0.008 & -0.004 & 0.030 \\
\hline Maximum & 14.661 & 9.11 & 14.661 \\
\hline Minimum & -9.019 & -7.935 & -9.019 \\
\hline Std. Dev. & 1.544 & 1.153 & 1.845 \\
\hline Skewness & 0.269 & 0.409 & 0.206 \\
\hline Kurtosis & 10.177 & 9.706 & 8.39 \\
\hline Observations & 2815 & 1382 & 1433 \\
\hline \multirow[t]{2}{*}{ Panel-B: } & \multicolumn{3}{|c|}{ MTRIN } \\
\hline & Full Smpl & $1^{\text {st }} \mathrm{SS}$ & $2^{\text {nd }} \mathrm{SS}$ \\
\hline Mean & 0.371 & 0.427 & 0.317 \\
\hline Median & 0.333 & 0.356 & 0.316 \\
\hline Maximum & 3.663 & 3.663 & 3.663 \\
\hline Minimum & -2.857 & -2.857 & -2.857 \\
\hline Std. Dev. & 1.075 & 1.218 & 0.913 \\
\hline Skewness & 0.090 & 0.074 & -0.018 \\
\hline Kurtosis & 4.274 & 3.386 & 5.688 \\
\hline Observations & 2815 & 1382 & 1433 \\
\hline \multirow[t]{2}{*}{ Panel-C: } & \multicolumn{3}{|c|}{ Amihud } \\
\hline & Full Smpl & $1^{\text {st }} \mathrm{SS}$ & $2^{\text {nd }} \mathrm{SS}$ \\
\hline Mean & 0.001 & 0.000 & 0.002 \\
\hline Median & 0.022 & 0.030 & 0.015 \\
\hline Maximum & 3.100 & 3.065 & 3.100 \\
\hline Minimum & -3.775 & -3.775 & -3.051 \\
\hline Std. Dev. & 0.714 & 0.747 & 0.680 \\
\hline Skewness & -0.202 & -0.185 & -0.221 \\
\hline Kurtosis & 5.102 & 4.799 & 5.419 \\
\hline Observations & 2815 & 1382 & 1433 \\
\hline
\end{tabular}

Table I provides some descriptive statistics of excess returns (Panel A) and our sentiment proxies - MTRIN (Panel B) and Amihud (Panel C), over the full sample and two sub-sample periods. Excess returns show typical characteristics of significant non-normality. Sub-sample comparison reveals that returns in the second sub-sample is much more volatile, which contains both the extreme return values (min and max) of the full sample period. Like that of returns, our sentiment shift measures also display significant non-normality. In comparison to the first sub-sample period, higher kurtosis values of alternative sentiment shift measures in the second sub-period may have resulted from some frequent large swings in sentiment values during the period.

\section{EMPIRICAL RESULTS}

Table II reports the results of estimating the GARCH specifications of equation (1) and (2) with and without the sentiment shift measures over the full sample and sub-sample periods. All GARCH specifications are estimated using the quasi-maximum likelihood method and standard errors of estimates are adjusted for heteroskedasticity [21]. To facilitate comparison, Panel A of the table reports the results of estimating the benchmark specification without the sentiment shift indicators. Interestingly, a negative and significant GARCH-in-mean term for the second sub-sample appears to contradict the CAPM prediction and implies a negative price for time-varying risk for the period. Estimates of the mean equation also support the presence of autocorrelation and the day-of-the-week effect in daily excess returns. Estimates of the variance equation highlight the difference in volatility dynamics in two sub-periods of analysis - while the asymmetric effect of negative return shocks is evident in the second sub-sample, we find no such evidence for earlier sub-sample period.

Panel B and C of the table present the effect of sentiment shifts on return and volatility dynamics where sentiment shifts are measured in terms of MTRIN and Amihud, respectively. The direct effect of sentiment shifts on excess returns is most clearly evident across measures and sub-periods of analysis. Judging by the size of the coefficients, sentiment shifts play a greater role affecting excess returns in periods when the market is more volatile. Focusing on the mean equation estimates, it is evident that the hold-more effect dominates the price-pressure effect in DSE and therefore the bullish (bearish) sentiment of noise traders leads to an increase (decrease) in expected returns.

Using both of our sentiment proxies we also find some evidence, particularly with reference to the first sub-sample of data, that the magnitude of sentiment shift may significantly affect the formation of conditional volatility in the market. Interestingly, our sub-period analysis suggests that the effect of sentiment shift on conditional volatility may be different depending on the overall market conditions. Specifically, using the MTRIN measure we find that a bearish shift in sentiment exert a negative effect on the volatility of future returns in a relatively tranquil period, the effect however turns positive during a relatively turbulent period of market activity. In addition, we find evidence that the introduction of sentiment in our GARCH-in-mean framework has the potential to turn the previously observed insignificant or negative expected return-volatility relationship into positive or only insignificantly negative one. Using MTRIN as the sentiment proxy for the full sample and the first sub-sample, we find evidence that as the magnitude of the bullish (bearish) shift in sentiment increases, there is an upward (a downward) revision in conditional volatility, which, given a positive expected return-volatility relationship, leads to an upward revision in expected returns. 
This result implies that the create-space effect of noise trading dominates its Friedman effect in the context of DSE.

\begin{tabular}{|c|c|c|c|}
\hline \multicolumn{4}{|l|}{ Panel-A: } \\
\hline & Full Smpl. & $1^{\text {st }} \mathrm{SS}$ & $2^{\text {nd }} \mathrm{SS}$ \\
\hline$\alpha_{0}$ & $-0.13 * *$ & $-0.164 \quad * *$ & 0.22 \\
\hline$\alpha_{1}$ & 0.052 & 0.089 & $-0.188 \quad *$ \\
\hline $\mathrm{AR}(1)$ & $0.109 * * *$ & $0.137 * * *$ & $0.069 * *$ \\
\hline $\mathrm{AR}(2)$ & -0.033 & -0.028 & $-0.053 *$ \\
\hline $\mathrm{AR}(3)$ & $0.047 * *$ & 0.024 & $0.048 *$ \\
\hline $\mathrm{AR}(4)$ & $0.043 * *$ & $0.084 * * *$ & -0.015 \\
\hline DAY1 & 0.048 & 0.071 & -0.049 \\
\hline DAY2 & $0.197 * * *$ & $0.151 * *$ & $0.274 * *$ \\
\hline DAY3 & $0.104 *$ & 0.1 & 0.097 \\
\hline DAY4 & $0.231 * * *$ & $0.146 * *$ & $0.383 * * *$ \\
\hline$\beta_{0}$ & $0.023 * * *$ & $0.014 * * *$ & $0.093 * * *$ \\
\hline$\beta_{1}$ & $0.129 * * *$ & $0.158 * * *$ & $0.069 * * *$ \\
\hline$\beta_{2}$ & $0.07 *$ & -0.009 & $0.172 * * *$ \\
\hline$\beta_{3}$ & $0.844 * * *$ & $0.857 * * *$ & $0.822 * * *$ \\
\hline $\mathrm{N}$ & 2815 & 1382 & 1433 \\
\hline Log Like. & -4580.42 & -1919.7 & -2624.11 \\
\hline Skw & 0.543 & 0.692 & 0.227 \\
\hline Kur & 6.636 & 9.345 & 3.771 \\
\hline $\mathrm{Q}(5)$ & $9.4 *$ & 3.224 & 3.843 \\
\hline$Q^{2}(5)$ & 3.29 & 1.665 & 6.407 \\
\hline
\end{tabular}

\begin{tabular}{|c|c|c|c|}
\hline \multicolumn{4}{|l|}{ Panel-B: } \\
\hline & Full Smpl. & $1^{\text {st }} \mathrm{SS}$ & $2^{\text {nd }} \mathrm{SS}$ \\
\hline$\alpha_{0}$ & $-0.348 * * *$ & $-0.361 * * *$ & $-0.266 *$ \\
\hline$\alpha_{1}$ & $0.083 *$ & $0.132 *$ & -0.064 \\
\hline$\alpha_{2}$ & $0.419 * * *$ & $0.335 * * *$ & $0.792 * * *$ \\
\hline $\mathrm{AR}(1)$ & $0.101 * * *$ & $0.13 * * *$ & $0.075 * * *$ \\
\hline $\operatorname{AR}(2)$ & -0.024 & -0.006 & -0.032 \\
\hline $\operatorname{AR}(3)$ & $0.041 * *$ & 0.032 & $0.04 *$ \\
\hline $\operatorname{AR}(4)$ & $0.032 *$ & $0.085 * * *$ & -0.028 \\
\hline DAY1 & $0.109 *$ & $0.129 *$ & 0.025 \\
\hline DAY2 & $0.294 * * *$ & $0.259 * * *$ & $0.316^{* * * *}$ \\
\hline DAY3 & $0.149 * *$ & $0.141 * *$ & 0.172 \\
\hline DAY4 & $0.23 * * *$ & $0.154 * *$ & $0.359 * * *$ \\
\hline$\beta_{0}$ & $0.021 * * *$ & 0.009 & $0.066 * * *$ \\
\hline$\beta_{1}$ & $0.109 * * *$ & $0.114 * * *$ & $0.065 * * *$ \\
\hline$\beta_{2}$ & $0.077 *$ & 0.041 & $0.114 * * *$ \\
\hline$\beta_{3}$ & $0.847 * * *$ & $0.853 * * *$ & $0.822 * * *$ \\
\hline$\beta_{4}$ & 0.012 & $0.017 *$ & 0.04 \\
\hline$\beta_{5}$ & $-0.009 *$ & $-0.009 * *$ & $0.166 * *$ \\
\hline $\mathrm{N}$ & 2815 & 1382 & 1433 \\
\hline Log Like. & -4320.11 & -1767.54 & -2466.52 \\
\hline Skw & 0.341 & 0.381 & 0.105 \\
\hline Kur & 5.818 & 7.813 & 3.82 \\
\hline $\mathrm{Q}(5)$ & 7.353 & 3.217 & 5.063 \\
\hline $\mathrm{Q}^{2}(5)$ & 9.206 & 2.176 & 5.731 \\
\hline
\end{tabular}

\begin{tabular}{lcll}
\hline Panel-C & $:$ & & \\
\hline & Full Smpl. & $1^{\text {st }} \mathrm{SS}$ & $2^{\text {nd }} \mathrm{SS}$ \\
\hline$\alpha_{0}$ & $-0.095^{*}$ & $-0.165 * * *$ & $0.341^{* *}$ \\
$\alpha_{1}$ & 0.047 & $0.123 * *$ & $-0.217 * *$ \\
$\alpha_{2}$ & $0.139 * * *$ & $0.044 *$ & $0.358 * * *$
\end{tabular}

\begin{tabular}{|c|c|c|c|}
\hline $\mathrm{AR}(1)$ & $0.11 * * *$ & $0.137 * * *$ & $0.061 * *$ \\
\hline $\mathrm{AR}(2)$ & -0.031 & -0.029 & $-0.052 *$ \\
\hline $\mathrm{AR}(3)$ & $0.049 * *$ & 0.021 & $0.047 *$ \\
\hline $\mathrm{AR}(4)$ & $0.044 * *$ & $0.098 * * *$ & -0.018 \\
\hline DAY1 & -0.013 & 0.022 & -0.144 \\
\hline DAY2 & $0.152 * *$ & $0.121 *$ & 0.177 \\
\hline DAY3 & 0.079 & 0.076 & 0.001 \\
\hline DAY4 & $0.207 * * *$ & 0.085 & $0.271 * *$ \\
\hline$\beta_{0}$ & $0.028 * * *$ & $0.013 * *$ & $0.088 * * *$ \\
\hline$\beta_{1}$ & $0.127 * * *$ & $0.158 * * *$ & $0.074 * * *$ \\
\hline$\beta_{2}$ & $0.089 * *$ & -0.009 & $0.184 * * *$ \\
\hline$\beta_{3}$ & $0.839 * * *$ & $0.857 * * *$ & $0.814 * * *$ \\
\hline$\beta_{4}$ & 0.004 & $0.052 * *$ & -0.112 \\
\hline$\beta_{5}$ & -0.023 & $-0.045 * * *$ & 0.123 \\
\hline $\mathrm{N}$ & 2815 & 1382 & 1433 \\
\hline Log Like. & -4565.94 & -1913.4 & -2603.78 \\
\hline Skw & 0.611 & 0.708 & 0.32 \\
\hline Kur & 6.54 & 9.305 & 3.694 \\
\hline $\mathrm{Q}(5)$ & 8.138 & 2.702 & 4.221 \\
\hline$Q^{2}(5)$ & 3.292 & 1.552 & $9.262 *$ \\
\hline
\end{tabular}

We investigate the impact of changes in noise trader sentiment on stock prices in the context of a frontier stock market - the Dhaka Stock Exchange, Bangladesh. We assess the effect of swings in sentiment on both the formation of conditional volatility and expected returns using daily stock data over the period from 1 January 2001 to 28 December 2012 in a generalized autoregressive conditional heteroskedasticity (GARCH) in-mean framework. Our primary measure of sentiment shifts is a modified trading index (TRIN) - a measure of the relative strength of the trading volume in relation to advancing stocks against that of declining stocks. We find that, irrespective of whether the market is in a relatively turbulent or tranquil state, daily excess returns are contemporaneously positively related to shifts in investor sentiment. In addition, depending on the market states, we uncover an asymmetric effect of the magnitude of bullish or bearish changes in sentiment on conditional volatility of future excess returns. While in a relatively volatile market conditions, the magnitude of only bearish change in sentiment leads to an upward revision in volatility, in a relatively stable market conditions, the magnitude of bullish (bearish) changes in sentiment leads to upward (downward) revisions in volatility. These results remain largely unaltered to the effect of outliers and an alternative measure of sentiment shift based on the changes in aggregate market liquidity. Overall, our empirical results show that the changes in investor sentiment in a frontier stock market like Bangladesh represent a systematic risk factor, which is priced in equilibrium.

\section{REFERENCES}

[1] J. M. Keynes, The General Theory of Employment, Interest and Money, London, Melbourne, Toronto: Macmillan, 1936, ch. 12.

[2] J. B. D. Long, A. Shleifer, L. H. Summers, and R. Waldmann, "Noise trader risk in financial markets," Journal of Political Economy, vol. 98, pp. 703-738, 1990.

[3] A. Shleifer and L. H. Summers, "The noise trader approach to finance," Journal of Economic Perspectives, vol. 4, pp. 19-33, 1990. 
[4] M. Schmeling, "Investor sentiment and stock returns: Some international evidence," Journal of Empirical Finance, vol. 16, pp 394-408, 2009.

[5] E. F. Fama, "Efficient capital markets: A review of theory and empirical work," Journal of Finance, vol. 25, pp. 383-417, 1970.

[6] R. Neal and M. S. Wheatley, "Do measures of investor sentiment predict returns?” Journal of Financial and Quantitative Analysis, vol. 33, pp. 523-547, 1998.

[7] G. W. Brown and M. T. Cliff, "Investor sentiment and the near-term stock market," Journal of Empirical Finance, vol. 11, pp. 1-27, 2004.

[8] G. W. Brown and M. T. Cliff, "Investor sentiment and asset valuation," Journal of Business, vol. 78, pp. 405-440, 2005.

[9] M. Baker and J. Wurgler, "Investor sentiment and the cross-section of stock returns," Journal of Finance, vol. 61, pp. 1645-1680, 2006.

[10] G. W. Brown, "Volatility, sentiment, and noise traders," Financial Analysts Journal, vol. 55, pp. 82-90, 1999.

[11] W. Y. Lee, C. X. Jiang, and D. C. Indro, "Stock market volatility, excess returns, and the role of investor sentiment," Journal of Banking \& Finance, vol. 26, pp. 2277-2299, 2002

[12] R. Beaumont, M.-V. Daele, B. Frijns, T. Lehnert, and A. Muller, "Investor sentiment, mutual fund flows and its impact on returns and volatility," Managerial Finance, vol. 34, pp. 772-785, 2008.

[13] Q. Zhang and S.-E. Yang, "Noise trading, investor sentiment volatility, and stock returns," Systems Engineering-Theory and Practice, vol. 29 , pp. 40-47, 2009.

[14] F. Wu et al., "The trading behaviour of institutions and individuals in Chinese equity markets," Journal of Banking \& Finance, vol. 31, pp. 2695-2710, 2007.

[15] G. Kling and L. Gao, "Chinese institutional investors' sentiment," Journal of International Financial Markets \& Money, vol. 18, pp. 374-387, 2008.

[16] D. B. Nelson, "Conditional heteroscedasticity in asset returns: A new approach,” Econometrica, vol. 59, pp. 347-370, 1991

[17] L. R. Glosten, R. Jagannathan, and D. A. Runkle, "On the relation between the expected value and the volatility of the nominal excess return on stocks," Journal of Finance, vol. 48, pp. 1779-1801, 1993.
[18] M. Baker and J. C. Stein, "Market liquidity as a sentiment indicator," Journal of Financial Markets, vol. 7, pp. 271-299, 2004.

[19] Y. Amihud, "Illiquidity and stock returns: cross-section and time series effects," Journal of Financial Markets, vol. 5, pp. 31-56, 2002.

[20] A. S. Kyle, "Continuous auctions and insider trading," Econometrica, vol. 53, pp. 1315-1336, 1985.

[21] T. Bollerslev and J. M. Wooldridge, "Quasi-maximum likelihood estimation and inference in dynamic models with time varying covariances," Econometrics Review, vol. 11, pp. 143-172, 1992.

M. Arifur Rahman is a senior lecturer at the Universiti Brunei Darussalam. He obtained his Ph.D. in Finance from the University of Western Sydney in Australia. His research interests are accounting information and asset prices, issue in behavioral finance and emerging stock market behavior. He has published in internationally refereed journals including the Review of Quantitative Finance and Accounting, Applied Financial Economics and Frontiers in Finance and Economics. Recently, he has also reviewed papers for the Quarterly Review of Economics and Finance.

Lim Kok Shien is a lecturer at Universiti Brunei Darussalam. He obtained his master in International Finance from University of New South Wales in Australia. His research interests are retirement planning and investments. He has provided numerous workshops for entrepreneurs and senior government officials on financial planning and retirement. He has also done consultancy work on determining contribution rates for retirement for the Brunei retirement provident fund.

M. Shibley Sadique is a senior lecturer at Curtin University, Malaysia. He obtained his Ph.D. in Finance from Monash University in Australia. His research interests are textual information and market behavior, nonlinearity in asset prices and behavioral finance. He has published in internationally refereed journals including Journal of Macroeconomics, International Journal of Finance \& Economics and Asian Economic Review. He has been reviewer in different international journals such as Economics Letters, Communications in Statistics-Simulation and Computation, Economic Notes - Review of Banking, Finance and Monetary Economics. 